\title{
An improved flower pollination solution for economic dispatch with valve point effect
}

\author{
Muhammad Iqbal ${ }^{1}$, Nazri Mohd Nawi ${ }^{2}$, Radiah Bt. Mohamad ${ }^{3}$ \\ 1,2,3 Faculty of Computer Science and Information Technology, Universiti Tun Hussein Onn Malaysia, Malaysia \\ ${ }^{1}$ Department of Computer Science, University of Lahore Japan Road, Islamabad, Pakistan
}

\begin{tabular}{l} 
Article Info \\
\hline Article history: \\
Received Aug 11, 2020 \\
Revised Feb 25, 2021 \\
Accepted Mar 30, 2021 \\
\hline
\end{tabular}

Keywords:

Crossover operator

Economic dispatch

Meta-heuristic

Valve point loading effect

Switch probability

\begin{abstract}
The economic dispatch (ED) is used to find the best optimal output of power generation at the lowest operating cost of each generator, to fulfill the requirements of the consumer. To get a practical solution, several constraints have to be considered, like transmission losses, the valve point effect, prohibited operating region, and emissions. In this research, the valve point effect is to be considered which increases the complexity of the problem due to its ripple effect on the fuel cost curve. Economic load dispatch problems are well-known optimization problems. Many classical and meta-heuristic techniques have been used to get better solutions. However, there is still room for improvement to get an optimal solution for the economic dispatch problem. In this paper, an improved flower pollination algorithm with dynamic switch probability and crossover operator is proposed to solve these complex optimization problems. The performance of our proposed technique is analyzed against fast evolutionary programming (FEP), modified fast evolutionary programming (MFEP), improved fast evolutionary programming (IFEP), artificial bee colony algorithm (ABC), modified particle swarm optimization (MPSO), and standard flower pollination algorithm (FPA) using three generator units and thirteen thermal power generation units, by including the effects of valve point loading unit and without adding it. The proposed technique has outperformed other methods in terms of the lowest operating fuel cost.
\end{abstract}

This is an open access article under the CC BY-SA license.

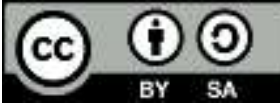

\section{Corresponding Author: \\ Muhammad Iqbal \\ Department of Computer Science \\ University of Lahore Japan Road \\ Islamabad, Pakistan \\ Email: iqbalmoeez@gmail.com}

\section{INTRODUCTION}

The Statistical survey of world energy shows that more than $60 \%$ of the total electricity is produced by thermal power generation [1]. In this modern era, the usage of technology is increasing tremendously. Moreover, electricity demand is also growing exponentially. Therefore, to overcome this gap, different means of power generation like hydropower, solar power, wind power, atomic power, and thermal power are adapted to provide an adequate balance between supply and demand. However, thermal power generation still plays a vital role to fulfill the requirement, and it is also feasible to install in a multi-environment. Fuels like natural gas, fossil, and coal are used to produce steam to run turbines for power generation. The valve controls the steam entering the turbine by using different nozzle groups (several valves are opened) to achieve the best efficiency at the given output. That is why the valve point loading effect is considered to control the fuel consumption in power generation. It is a non-linear complex objective function that contains 
many constraints such as cost coefficients with a sinusoidal function. In the last thirty years, many techniques have been established to minimize the cost of power generation by optimal scheduling of the generators within its limits.

Some well-known conventional techniques like lambda iteration [2], quadratic programming [3], and other gradient methods are used to solve the nonlinear economic dispatch (ED) problems. These methods require smooth, incremental cost, but practically, the input and output of the generators are always piece-wise nonlinear because each generator has its non-smooth cost curve, as shown in Figure 1. Therefore, in solving such non-convex problems, some derivative techniques have dimensionality issues and complications with time management. Since the meta-heuristic algorithms are population-based, using many solution candidates to estimate the best solution, they hold an advantage in getting optimal solutions over classical methods that use single solution techniques. In the literature, many bio-inspired and evolutionary techniques have been applied to solve economic dispatch (ED) problems, such as genetic algorithm (GA) [4] and harmony search algorithms [5], [6], that are used with valve point loading effect. The modified Tabu Search (MTS) algorithm was applied on ED non-smooth function with multiple minima [7] and particle swarm optimization (PSO) and modified particle swarm optimization [8] were also used to improve the results. The flower pollination algorithm [9] and its modified version have been implemented to solve the combined economic load dispatch problems [10]. Furthermore, some hybrid techniques have been introduced to address the complex economic dispatch (ED) problems [1], [11]. The flower pollination algorithm has been applied in the field of power distribution to analyse the optimality of capacitors in case of placement (allocation) and sizing [12]. On the other hand, it is also used to optimize the parameters of static VAR compensators for multi-machine power systems [13].

In this paper, an improved flower pollination algorithm with dynamic switch probability and cross over operator (IFPDS) is proposed to solve the ED problems including the valve point load effect. This method is easy to implement due to its fewer parameters, excellent ability to search, and effective convergence rate. The performance of the proposed algorithm in terms of the optimal solution has been compared with artificial bee colony (ABC) [14], standard flower pollination algorithm (FPA), and other discussed algorithms. This paper has divided into main five parts. In the second section, the economic dispatch problem is explained with the valve point effect and the third part is consisting of the proposed methodology. In the fourth section, the results are discussed with graphs. In the end, the paper is concluded with its future work.

\section{PROBLEM FORMULATION OF ED}

The economic dispatch is used to determine the operating fuel cost of every generator at its optimal power generation. The Economic dispatch problems are complex optimization problems with generic objective function:

$$
\text { in } \sum_{\mathrm{i}=1}^{\mathrm{n}} \mathrm{Fc}_{\mathrm{i}} \mathrm{P}_{\mathrm{i}}
$$

where $\mathrm{Fc}_{\mathrm{i}}$, represents the fuel cost of the given generator ' $\mathrm{i}$ ' to produce power $\mathrm{P}_{\mathrm{i}}$.

The equality and inequality constraints are:

$$
\begin{gathered}
\mathrm{P}_{\mathrm{d}}=\sum_{\mathrm{i}=1}^{\mathrm{n}} \mathrm{P}_{\mathrm{i}}-\mathrm{P}_{\mathrm{l}} \\
\mathrm{P}_{\mathrm{i}}^{\min } \leq \mathrm{P}_{\mathrm{i}} \leq \mathrm{P}_{\mathrm{i}}^{\max }
\end{gathered}
$$

where, $\mathrm{P}_{\mathrm{d}}$ is the power of demand for the system and $\mathrm{P}_{1}$ represents the power transmission losses. In the inequality constraint power capacity of each generator is lemmatized with minimum power $P_{i}^{\text {min }}$ and maximum power $\mathrm{P}_{\mathrm{i}}^{\max }$.

The quadratic function of fuel cost without valve point loading effect is given by;

$$
f\left(P_{i}\right)=a_{i} P_{i}^{2}+b_{i} P_{i}+c_{i}
$$

In this case, the thermal power generation is considered that has multi-valves point steam turbines. These turbines have a different input-output convex curve at each steam valve point results in a ripple in Figure 1 [4], [15]. Therefore, the problem is composed of a combination of quadratic function and superposition of sinusoidal function which contains multiple optima. The non-smooth cost function with valve point loading effect can be represented as: 


$$
\mathrm{F}_{\mathrm{t}}=\mathrm{a}_{\mathrm{i}} \mathrm{P}_{\mathrm{i}}^{2}+\mathrm{b}_{\mathrm{i}} \mathrm{P}_{\mathrm{i}}+\mathrm{c}_{\mathrm{i}}+\left|\mathrm{e}_{\mathrm{i}} * \sin \left(\mathrm{f}_{\mathrm{i}} *\left(\mathrm{P}_{\mathrm{i}}^{\mathrm{min}}-\mathrm{P}_{\mathrm{i}}\right)\right)\right|
$$

where, $a_{i}, b_{i}$ and $c_{i}$ are the cost co-efficient of each generator and $e_{i}, f_{i}$ are the coefficient of the valve point effect for each turbine [16], [17].

When the sinusoidal function is added to the quadratic function of the fuel cost of the generator then the ripple effect of the valve point loading effect makes the cost function more complex as in Figure 1. In solving this complicated problem, stochastic techniques are useful to get the optimal solution.

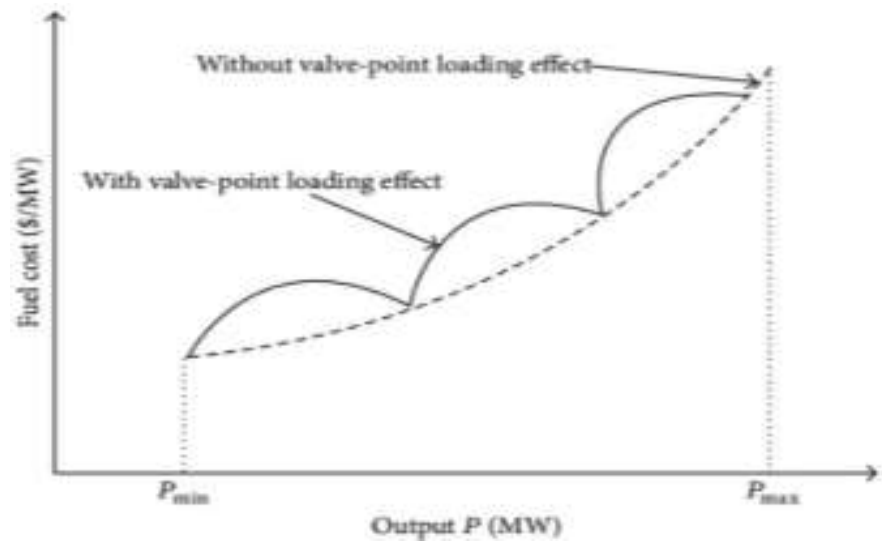

Figure 1. Valve point loading effect and the dotted line represents the quadratic cost

\section{THE PROPOSED METHOD}

The standard flower pollination algorithm (FPA) was introduced by Xing-She Yang [18]. It is a meta-heuristic, nature-inspired, and stochastic technique. The author learns the pollination behavior of the flowers to pollinate for its survival. Some flowers only attract those insects that help in the pollination process. These insects play the primary role as pollinators in global pollination. The main focus was to address the complex problems which were not tackled adequately by conventional methods. There are mainly two types of pollination:

- Biotic: it is long distance, cross-pollination which needs some pollinator to perform, like birds, bees, insects. So, for long-distance, he used levy's flight that behaves like a global search. It covers $90 \%$ of pollination.

- Abiotic: it occurs within the flower means self-pollination or local pollination, which no need for pollinators. It is only $10 \%$ of pollination.

Other characteristics of the pollination process like flower constancy that can be conceived as the reproduction probability are directly proportional to the similarity of two flowers involved and switch probability $\mathrm{p} \varepsilon[0,1]$ that controls both local pollination and global pollination. Global pollination is ensured through insects that are the fittest reproduction. If it is represented by " $\mathrm{g}$ *" then the relation of global pollination:

$$
x_{i}^{t+1}=x_{i}^{t}+\gamma L(\Lambda)\left(x_{i}^{t}-g^{*}\right)
$$

In (6) ' $x_{i}$ ' represents the solution vector at iteration $\mathrm{t}$, and $\mathrm{g}^{*}$ is the current best solution among all iterations. Here ' $\gamma$ ' is the scaling factor to control the step size [19]. In (7) where ' $L(K)$ ' is the controlling parameter that corresponds to the strength of pollination and uses levy's flight ' $\mathrm{L}$ ' (which is step size) for long random walk $\mathrm{L}>0$

$$
\mathrm{L} \sim\left[\Lambda \Gamma(\Lambda) \frac{\operatorname{sine}\left(\frac{K \pi}{2}\right)}{\pi \mathrm{s}(\Lambda+1)}\right] \quad \mathrm{s} \gg \mathrm{s}_{0}>0
$$

where $\Gamma(\Lambda)$ is the Gamma function[20].

The local pollination is expressed in (3).

$$
x_{i}^{t+1}=x_{i}^{t}+\in\left(x_{j}^{t}-x_{k}^{t}\right)
$$


In (8) where $x_{j}$ and $x_{k}$ are the two random pollens which are selected from different flowers of the same species of the plant. That will essentially mimic the flower constancy in a restricted neighborhood. Mathematically, if $x_{j}^{t}$ and $x_{k}^{t}$ come from the same species or selected from the same population that equivalently becomes a local random walk while $\in$ is randomly selected from a uniform distribution and to avoid immature convergence and to increase its optimality $\in$ is replaced with $\beta \in\{0.1,0.5\}$ [21], [22] and the selection criteria of pollens is defined

$$
x_{i}^{t+1}=x_{i}^{t}+\beta\left(x_{j}^{t}-x_{k}^{t}\right)
$$

where $x_{j}$ and $x_{k}$ are different pollens using selection criteria.

The proposed technique has a novelty to handle multi-constraints optimization problems. Due to the fewer number of parameters, it is so efficient and easy to implement. Figure 2 shows the flow chart of the improved flower pollination algorithm (IFPDS). The improved flower pollination algorithm using dynamic switch probability and crossover operator (IFPDS) is applied to solve the complex economic load dispatch optimization problem which can address the immature convergence problem by introducing the crossover operator to increase the diversity of the population in the local search process.

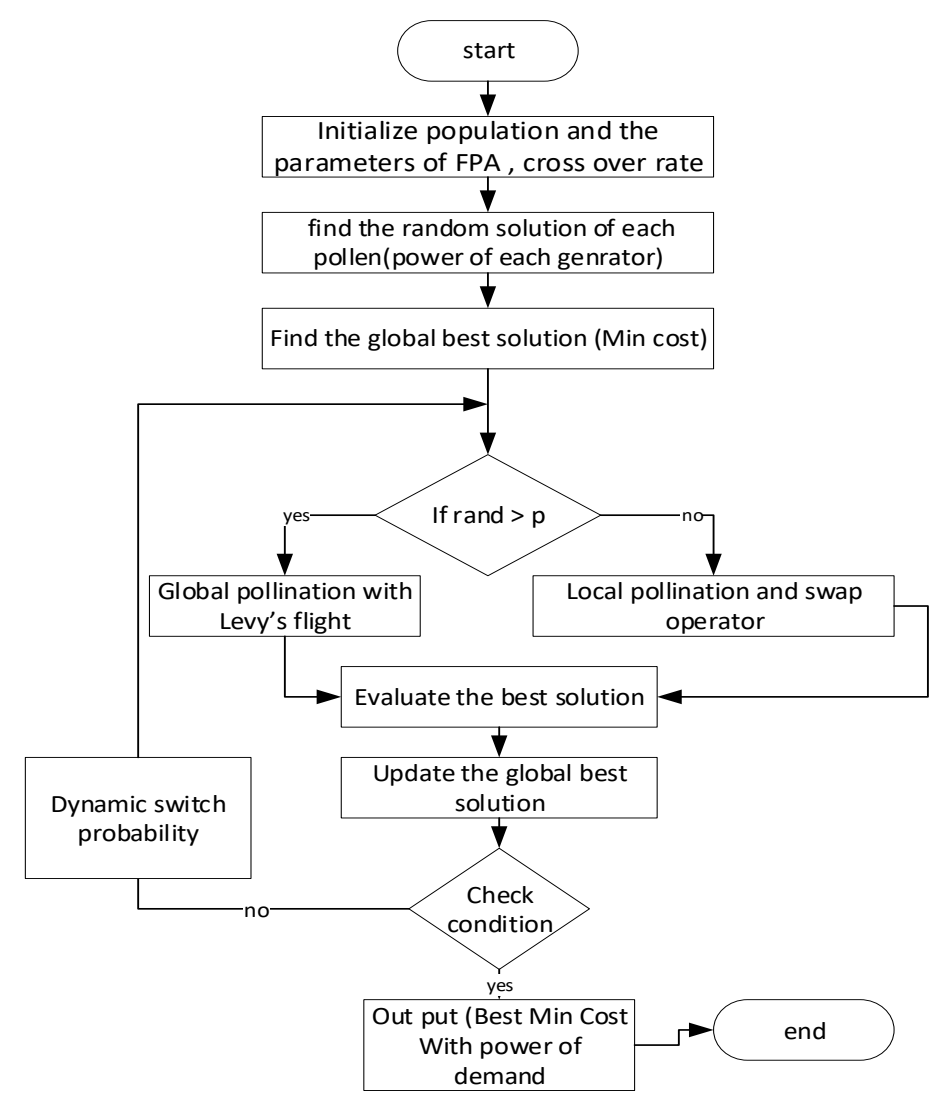

Figure 2. Flow chart Improved flower pollination algorithm with dynamic switch probability and crossover operator

The Crossover operator is explained in the following equation.

$$
\begin{aligned}
& S_{i}^{t+1}=\left\{\begin{array}{ccc}
y_{i, k} & \operatorname{rand}_{i, k}\left[\begin{array}{cc}
0 & 1
\end{array}\right]<C_{\mathrm{r}} \\
\mathrm{S}_{\mathrm{i}, \mathrm{k}}^{\mathrm{t}} & \text { else } & \mathrm{i}=1,2,3 \ldots \ldots \ldots, \mathrm{n}
\end{array}\right. \\
& \text { k } 1,2,3 \ldots \ldots, d
\end{aligned}
$$

In (10), $s_{i}^{k}$ is the $\mathrm{k}^{\text {th }}$ dimension of solution vector ' $\mathrm{i}$ ' and $\mathrm{Cr}$, is the crossover rate set 0.3 in this algorithm to diversify the population in local optimum to avoid the immature convergence [23], [24]. 
On the other hand, the fixed switch probability $(\mathrm{p}=0.8)$ is used in the standard flower pollination algorithm, which creates biasedness between exploration and exploitation. The proposed approach will use dynamic switch probability to increase the searchability by the balance between exploration and exploitation of the algorithm. The Dynamic switch probability has been represented by the given (11), [25].

$$
\mathrm{P}=0.6+0.2\left(\operatorname{Max}_{\text {iter }}-\mathrm{t}\right) / \mathrm{Max}_{\text {iter }}
$$

In (11), Max $_{\text {iter }}$ is the total number of iterations and ' $t$ ' is represents the current iteration.

\subsection{The pseudo-code of the proposed algorithm}

The pseudo-code of the proposed algorithm starts with the initialization of population, cross-over rate, and switch probability. After that global and local pollination will occur. In local pollination, the swap operator is introduced. In the end, the best solution is updated then dynamic switch probability is used for the next iteration.

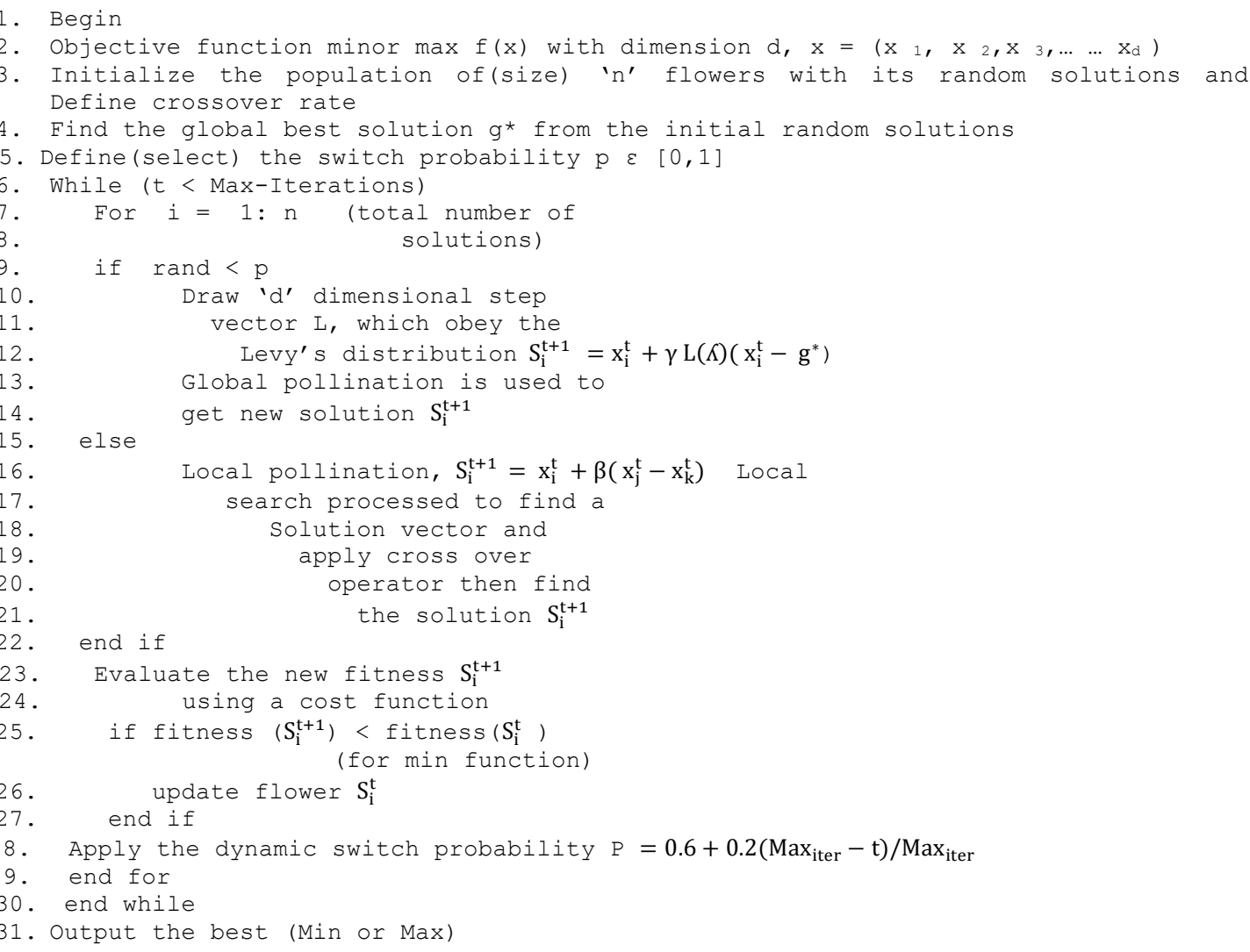

\section{RESULTS WITH ANALYSIS}

The performance of the proposed method has been evaluated by using two types of case studies in the economic dispatch problem, first one three thermal power generators, and the second thirteen power generators system. The statistical results of IFPDS have been compared with meta-heuristic algorithms FPA, $\mathrm{ABC}$, and MPSO [8].

\subsection{Case study I: Three generators (including valve point effect)}

The data given in Table 2 [8] of three thermal generators system for economic dispatch with non-convex cost function including valve point effect and the demand for power generation is $850 \mathrm{MW} / \mathrm{h}$. The sinusoidal objective function with valve point effect in (5) is considered to minimize the power generation cost. The IFPDS, SFPA, and ABC algorithms are applied to find the minimum fuel cost under the limited constraints. Each algorithm has run thirty times independently to analyze the performance. The statistical analysis is given in Table 3 by obtaining thirty independent runs of each algorithm. In this table minimum cost, maximum cost, mean cost, and standard deviation are calculated to compare the performance of all algorithms. 
In Table 3 the performance of SFPA, ABC, and MPSO algorithm (where genetic algorithm (GA), evolutionary programming (EP), and improved evolutionary programming (IEP) have been already evaluated in [8]) are compared with the proposed algorithm to represent the efficiency of the nature-inspired algorithm and different evolutionary algorithms. The statistical analysis of all algorithms proves that the proposed IFPDS algorithm has outperformed than other algorithms in getting the minimum cost of thermal power generation to fulfill the demand. In Figure 3, the graphs of meta-heuristic algorithms represent the convergence of each algorithm and the red line represents the convergence rate of the proposed algorithm. The edges of the graphs indicate the superiority of the proposed algorithm.

Table 2. Data for three generators with valve point effect

\begin{tabular}{cccccccc}
\hline Generator & $\mathrm{P} \min$ & $\mathrm{P} \max$ & $\mathrm{A}$ & $\mathrm{B}$ & $\mathrm{c}$ & $\mathrm{e}$ & $\mathrm{F}$ \\
\hline 1 & 100 & 600 & 0.001582 & 7.92 & 561 & 300 & 0.0315 \\
2 & 50 & 200 & 0.00482 & 7.97 & 78 & 150 & 0.063 \\
3 & 100 & 400 & 0.00194 & 7.86 & 310 & 200 & 0.042 \\
\hline
\end{tabular}

Table 3. Statistical results of algorithms with valve point effect

\begin{tabular}{lcccc}
\hline Algorithm & Min Cost & Max -Cost & Mean Cost & Standard dev. \\
\hline IFPDSO & 8204.31 & 8233.98 & 8215.556 & 9.006109 \\
MPSO[8] & 8234.07 & $/ /$ & $/ /$ & $/ /$ \\
FPA & 8206.37 & 8339.32 & 8229.182 & 25.79669 \\
ABC & 8210.83 & 8329.64 & 8271.365 & 30.47666 \\
\hline
\end{tabular}

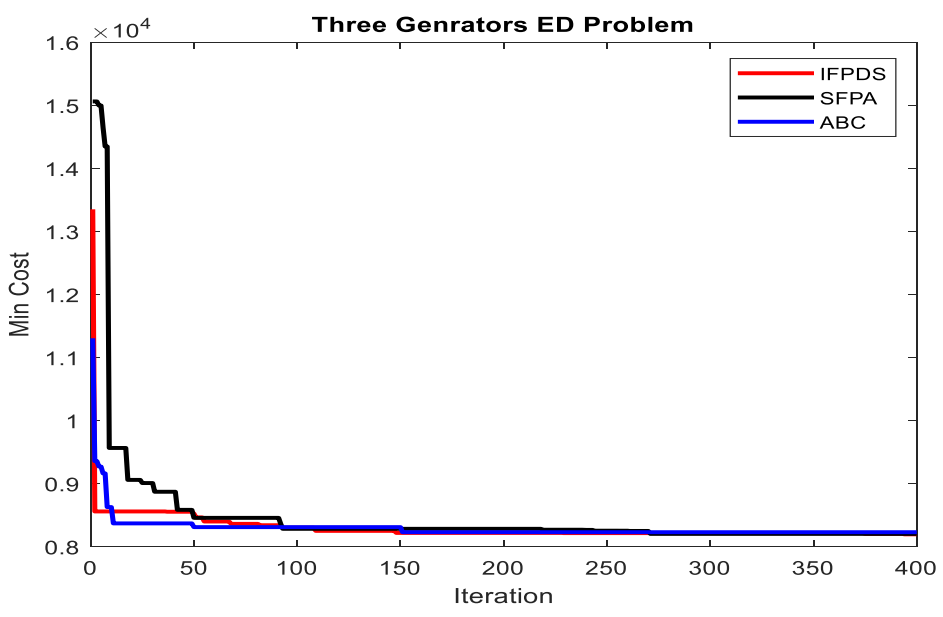

Figure 3. Minimum cost of fuel for three generators

\subsection{Case study I: Three generators (without valve point effect)}

Table 4, represents the power generation of each generator to generate the electricity of demand 850 $\mathrm{MW} / \mathrm{h}$ with its minimum fuel cost using quadratic cost function without a valve point loading effect. In this case study, it is clear from the results that improved flower pollination with switch probability and crossover operator algorithm (IFPDS) has performed better than the standard flower pollination algorithm (FPA) and artificial bee colony algorithm (ABC).

Table 4. Minimum fuel cost with its generations without valve point effect

\begin{tabular}{ccccc}
\hline Algorithm & P 1 & P 2 & P3 & Minimum Cost \\
\hline IFPDS & 391.1858 & 124.2041 & 334.6101 & 8197.4442 \\
FPA & 349.634 & 123.3567 & 332.01 & 8197.577 \\
ABC & 390.5147 & 123.1905 & 336.294 & 8199.9336 \\
\hline
\end{tabular}

\subsection{Case study II: Thirteen generators (including valve point effect)}

In this case study, thirteen thermal power generators are considered to increase the complexity of objective function with the valve point effect. Table 5 represents the data of fuel cost coefficients thirteen 
generators with a valve point loading effect. The algorithms such as ABC, SFPA, and IFPDS have been applied to minimize the cost of fuel to meet the demand $(1800 \mathrm{MW} / \mathrm{h})$ of thermal power generation. All algorithms have been run for thirty times independently. The results of each algorithm are shown in Table 6. It is evident from the analysis of the output data that the proposed IFPDS algorithm has performed better than the ABC and FPA concerning the average fuel cost of power generation. Demand $=1800 \mathrm{MW}$

In Figure 4, the graphs of nature-inspired stochastic algorithms have been plotted to compare the convergence rate of the proposed algorithm (IFPDS) with other algorithms. The red line in the graph represents the output of the proposed IFPDS algorithm which shows the best performance in case of lower cost among the algorithms such as ABC and FPA.

Table 5. Data for fuel cost co-efficient of thirteen generators

\begin{tabular}{cccccccc}
\hline Generator & $\mathrm{P} \min$ & $\mathrm{P} \max$ & $\mathrm{A}$ & $\mathrm{b}$ & $\mathrm{c}$ & $\mathrm{E}$ & $\mathrm{F}$ \\
\hline 1 & 0 & 680 & 0.00028 & 8.1 & 550 & 300 & 0.035 \\
2 & 0 & 360 & 0.00056 & 8.1 & 309 & 200 & 0.42 \\
3 & 0 & 360 & 0.00056 & 8.1 & 307 & 200 & 0.42 \\
4 & 60 & 180 & 0.00324 & 7.74 & 240 & 150 & 0.036 \\
5 & 60 & 180 & 0.00324 & 7.74 & 240 & 150 & 0.036 \\
6 & 60 & 180 & 0.00324 & 7.74 & 240 & 150 & 0.036 \\
7 & 60 & 180 & 0.00324 & 7.74 & 240 & 150 & 0.036 \\
8 & 60 & 180 & 0.00324 & 7.74 & 240 & 150 & 0.036 \\
9 & 60 & 180 & 0.00324 & 7.74 & 240 & 150 & 0.036 \\
10 & 40 & 120 & 0.00284 & 8.6 & 126 & 100 & 0.084 \\
11 & 40 & 120 & 0.00284 & 8.6 & 126 & 100 & 0.084 \\
12 & 55 & 120 & 0.00284 & 8.6 & 126 & 100 & 0.084 \\
13 & 55 & 120 & 0.00284 & 8.6 & 126 & 100 & 0.084 \\
\hline
\end{tabular}

Table 6. Statistical analysis of all algorithms (with valve point effect)

\begin{tabular}{ccccc}
\hline Algorithm & Min- Cost & Max -Cost & Mean- Cost & Standard deviation \\
\hline IFPDSO & 17996.45 & 18145.56 & 18097.2 & 29.8408 \\
FPA & 18103.54 & 18194.08 & 18121.53 & 39.44098 \\
ABC & 18110.87 & 18623.39 & 18406.12 & 128.8278 \\
\hline
\end{tabular}

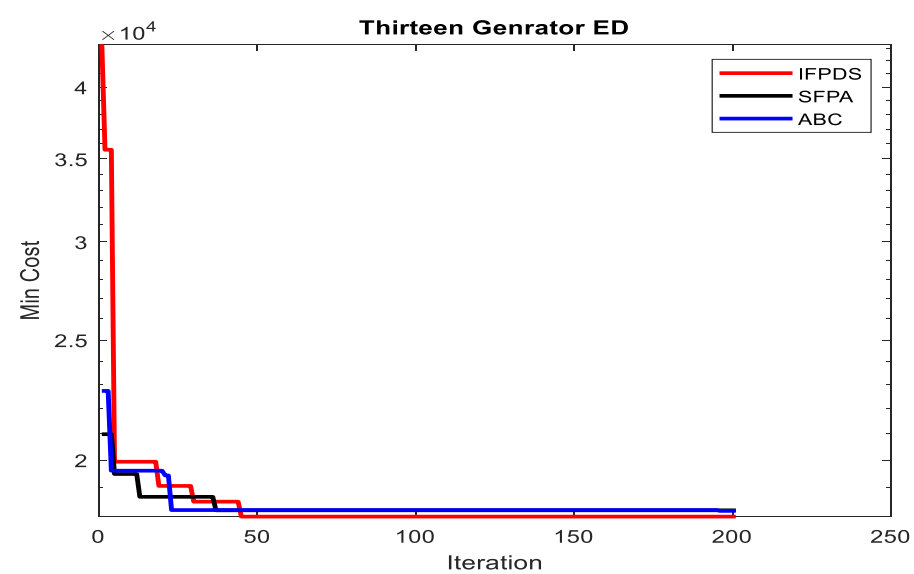

Figure 4. Minimum cost of fuel for thirteen generators

\subsection{Case study II: Thirteen generators (without valve point effect)}

Table 7, represents the power generation of each generator to generate the electricity of demand $1800 \mathrm{MW} / \mathrm{h}$ with its minimum fuel cost using quadratic cost function without a valve point loading effect. In this case, study results show that the improved flower pollination with switch probability and crossover operator algorithm (IFPSD) has outperformed better than the standard flower pollination algorithm (SFPA) and artificial bee colony algorithm (ABC), in achieving the lowest fuel cost. 
Table 7. Minimum fuel Cost with its generations without valve point effect

\begin{tabular}{|c|c|c|c|c|c|c|c|c|c|c|c|c|c|c|}
\hline Algo & P 1 & P 2 & P 3 & $\mathrm{P} 4$ & P 5 & P 6 & P 7 & P 8 & P9 & P 10 & P11 & $\mathrm{P} 12$ & P13 & Minimum Cost \\
\hline IFPDS & 498.2 & 247.4 & 281.5 & 112.6 & 124.5 & 76.5 & 74.7 & 101.2 & 69.5 & 40 & 44.4 & 57.5 & 72.1 & 17961.91 \\
\hline $\mathrm{ABC}$ & 482.7 & 254.5 & 190.5 & 136.5 & 108.6 & 60 & 81.8 & 123.3 & 132.6 & 45.4 & 40 & 88.7 & 55 & 8199.93 \\
\hline
\end{tabular}

\section{CONCLUSION}

The proposed algorithm IFPDS has been applied to solve economic dispatch (ED) problems using non-smooth fuel cost, with and without valve point effect. The simulation results are tabulated for comparison. It is evident from the results that the proposed IFPDS has minimized the cost of fuel better than the other mentioned algorithms. The convergence ability has been observed by comparing graphical results with other nature-inspired meta-heuristic techniques. The overall performance of the proposed IFPDS indicates that in the future, this method will be an important tool to solve the complex optimization problems of the multi-machine system, distribution system, and power generation systems, including transmission line losses to minimize the expense of power generation and emission cost to clean the environment.

\section{ACKNOWLEDGEMENTS}

The authors would like to express the deepest appreciation to the Ministry of Education Malaysia for financially supporting this Research under Trans-disciplinary Research Grant Scheme (TRGS-Vote number T003). Additional supports in terms of facilities also provided by Centre Soft Computing and Data Mining Centre (SMC), FSKTM, Universiti Tun Hussein Onn Malaysia (UTHM).

\section{REFERENCES}

[1] C. L. Huang et al., "A new Method for Dynamic Economic Emission Dispatch Problem," 2019 IEEE Congr. Evol. Comput. CEC 2019 - Proc., pp. 2355-2361, 2019, doi: 10.1109/CEC.2019.8790238.

[2] D. O. Dike, M. I. Adinfono, and G. Ogu, "Economic dispatch of generated power using modified lambda-iteration method," IOSR J. Electr. Electron. Eng., vol. 7, no. 1, pp. 49-54, 2013, doi:10.9790/1676-0714954.

[3] G. F. Reid and L. Hasdorff, "Economic dispatch using quadratic programming," IEEE Trans. Power Appar. Syst., vol. PAS-92, no. 6, pp. 2015-2023, 1973, doi: 10.1109/TPAS.1973.293582.

[4] D. C. Walters and G. B. Sheble, "Genetic algorithm solution of economic dispatch with valve point loading," IEEE Trans. Power Syst., vol. 8, no. 3, pp. 1325-1332, 1993, doi: 10.1109/59.260861.

[5] T. Ratniyomchai, A. Oonsivilai, P. Pao-la-or, and T. Kulworawanichpong, "Economic load dispatch using improved harmony search," WSEAS Trans. Syst. Control, vol. 5, no. 4, pp. 248-257, 2010.

[6] M. A. Al-Betar, M. A. Awadallah, A. T. Khader, A. L. Bolaji, and A. Almomani, "Economic load dispatch problems with valve-point loading using natural updated harmony search," Neural Comput. Appl., vol. 29, no. 10, pp. 767-781, 2018, doi:10.1007/s00521-016-2611-2.

[7] W. Lin, F. Cheng, and M. Tsay, "An Improved Tabu Search for Economic Dispatch," Power, vol. 17, no. 1, pp. 108-112, 2002, doi:10.1109/MPER.2002.4311692.

[8] J. B. Park, K. S. Lee, J. R. Shin, and K. Y. Lee, "A particle swarm optimization for economic dispatch with nonsmooth cost functions," IEEE Trans. Power Syst., vol. 20, no. 1, pp. 34-42, 2005, doi: 10.1109/TPWRS.2004.831275

[9] R. Prathiba, M. Balasingh Moses, and S. Sakthivel, "Flower pollination algorithm applied for different economic load dispatch problems," Int. J. Eng. Technol., vol. 6, no. 2, pp. 1009-1016, 2014.

[10] H. M. Dubey, M. Pandit, and B. K. Panigrahi, "A Biologically Inspired Modified Flower Pollination Algorithm for Solving Economic Dispatch Problems in Modern Power Systems," Cognit. Comput., vol. 7, no. 5, pp. 594-608, 2015, doi:10.1007/s12559-015-9324-1.

[11] X. Wang and K. Yang, "Economic load dispatch of renewable energy-based power systems with high penetration of large-scale hydropower station based on multi-agent glowworm swarm optimization," Energy Strateg. Rev., vol. 26, p. 100425, 2019, doi:10.1016/j.esr.2019.100425.

[12] A. Y. Abdelaziz, E. S. Ali, and S. M. Abd Elazim, "Flower Pollination Algorithm and Loss Sensitivity Factors for optimal sizing and placement of capacitors in radial distribution systems," Int. J. Electr. Power Energy Syst., vol. 78, pp. 207-214, 2016, doi: 10.1016/j.ijepes.2015.11.059.

[13] A. Y. Abdelaziz and E. S. Ali, "Static VAR Compensator Damping Controller Design Based on Flower Pollination Algorithm for a Multi-machine Power System,” Electr. Power Components Syst., vol. 43, no. 11, pp. 1268-1277, 2015, doi: 0.1080/15325008.2015.1028116.

[14] R. Subramanian, K. Thanushkodi, and A. Prakash, "An efficient meta heuristic algorithm to solve economic load dispatch problems," Iran. J. Electr. Electron. Eng., vol. 9, no. 4, pp. 246-252, 2013.

[15] N. Sinha, R. Chakrabarti, and P. K. Chattopadhyay, "Evolutionary programming techniques for economic load dispatch," IEEE Trans. Evol. Comput., vol. 7, no. 1, pp. 83-94, 2003, doi: 10.1109/TEVC.2002.806788.

[16] S. Komsiyah, D. Suhartono, and Budiyanto, "Optimization economic dispatch with transmission losses using by 
firefly algorithm," AIP Conf. Proc., vol. 1746, 2016 doi: 10.1063/1.4953968.

[17] A. Y. Abdelaziz, E. S. Ali, and S. M. Abd Elazim, "Implementation of flower pollination algorithm for solving economic load dispatch and combined economic emission dispatch problems in power systems," Energy, vol. 101, pp. 506-518, 2016, doi: 10.1016/j.energy.2016.02.041.

[18] X. S. Yang, M. Karamanoglu, and X. He, "Multi-objective flower algorithm for optimization," Procedia Comput. Sci., vol. 18, pp. 861-868, 2013, doi: 10.1016/j.procs.2013.05.251.

[19] X. S. Yang, M. Karamanoglu, and X. He, "Flower pollination algorithm: A novel approach for multiobjective optimization," Eng. Optim., vol. 46, no. 9, pp. 1222-1237, 2014, doi:10.1080/0305215X.2013.832237.

[20] I. Pavlyukevich, "Lévy flights, non-local search and simulated annealing," J. Comput. Phys., vol. 226, no. 2, pp. 1830-1844, 2007, doi: 10.1016/j.jcp.2007.06.008.

[21] D. Lazim, A. M. Zain, M. Bahari, and A. H. Omar, "Review of modified and hybrid flower pollination algorithms for solving optimization problems," Artif. Intell. Rev., pp. 1-31, 2017, doi: 10.1007/s10462-017-9580-4.

[22] R. Salgotra and U. Singh, "Application of mutation operators to flower pollination algorithm," Expert Syst. Appl., vol. 79, pp. 112-129, 2017, doi: 10.1016/j.eswa.2017.02.035.

[23] D. Chakraborty, S. Saha, and O. Dutta, "DE-FPA: A hybrid differential evolution-flower pollination algorithm for function minimization," 2014 Int. Conf. High Perform. Comput. Appl. ICHPCA 2014, 2015.

[24] X. He, X. S. Yang, M. Karamanoglu, and Y. Zhao, "Global Convergence Analysis of the Flower Pollination Algorithm: A Discrete-Time Markov Chain Approach,” Procedia Comput. Sci., vol. 108, pp. 1354-1363, 2017, doi: 10.1016/j.procs.2017.05.020.

[25] T. Ratniyomchai et al., "Preface," Stud. Comput. Intell., vol. 7, no. 1, pp. v-vi, 2016.

\section{BIOGRAPHIES OF AUTHORS}
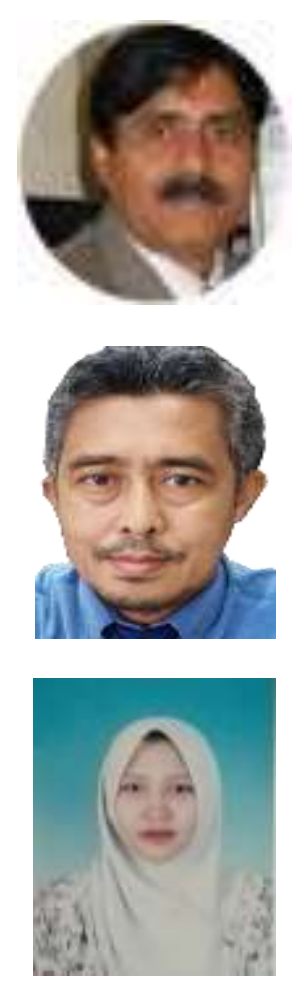

Assistant Prof. Muhammad Iqbal Kamboh.PhD student at Universiti Tun Hussein Onn Malaysia (UTHM) Faculty member at the department of Computer Science and Information Technology The University of Lahore Pakistan.

Prof. Dr. Nazri Bin Mohd Nawi Head of Soft Computing \& Data Mining (SMC) Faculty of Computer Science and Information Technology (FSKTM), Universiti tun Hussein Onn Malaysia (UTHM),86400, Parit Raja, Batu Pahat, Johor, Malaysia.

Dr. Radiah Bt. Mohamad Senior Lecturer at Faculty of Computer Science and Information Technology (FSKTM), Universiti tun Hussein Onn Malaysia (UTHM) 86400, Parit Raja, Batu Pahat, Johor, Malaysia. 